\title{
Simulation of Drainage Cleaning Robotics System using Solid Work Tinkercad software
}

\author{
Mobina Salim Sanadi \\ Department of Electrical Engineering \\ ATS's Sanjay Bhokare Group of Institutes, \\ Miraj. \\ Sangli, INDIA. \\ mobinasanadi@gmail.com
}

\author{
Priyanka Sardar Satpute \\ Department of Electrical Engineering \\ ATS's Sanjay Bhokare Group of Institutes, \\ Miraj. \\ Sangli, INDIA. \\ priyankasatpute.6615@gmail.com
}

\author{
Mazharhussain N. Mestri \\ Department of Electrical Engineering \\ ATS's Snajay Bhokare Group of institutues, \\ Miraj. \\ Sangli, INDIA. \\ mnmestri@gmail.com
}

\begin{abstract}
In this paper we are designing simulation using tinkercad solid work software for simulation. In simulation we used pulse width modulation (PWM) to provide very smooth action and speed varieties for PWM pulse we used ATmega2560 microcontroller.
\end{abstract}

In this design we used robotic system which can reduce the complex mechanism for cleaning the manhole.it will give a clear understanding of the manipulator and its subsystem interactions.

Index Terms- tinkercad solid work software, pulse width modulation (PWM) ATmega2560 microcontroller. Simulation, Motor Driver IC (Integrated Circuit), pulse width modulation (PWM). DCRS (drainage cleaning robotic system).

\section{INTRODUCTION}

The motive of the project is to automate the sewage cleaning process in drainage. In this process man has to enter the hole to cleaning using with some basic equipment like shovel and spade. Currently manual sewage banned in our country but there is requirement of some devices to clean the man hole without entering it so we introduce robotic arm system such that the robotic arm will grab the sewage. In this system we use thinker cad solid work software for design. The part of modulation contain four legs with height $96 \mathrm{~cm}$ which provide stability. The robotic arm length $100 \mathrm{~cm}$ and used to perform main cleaning action we design four wheel drive which provide better movement under drainage. The PWM ATmega2560 microcontroller used and also tinkercad software used.PWM basically help to run motor at various speed

\section{BLOCK DIAGRAM}

In this design we used Tinkercad solid work software for design. Design start with manual drawing. After Rough paper drawing, we modulate all the parts which we design. This modulation process done by using tinkercad solid work software. After modulation there is one phase that is parts are appropriate or not. If part is appropriate then is goes to assemble the part if it is not appropriate it goes to again part modulation. In part modulation again these parts ae rectifying. This cycle is continuing and repetitive.

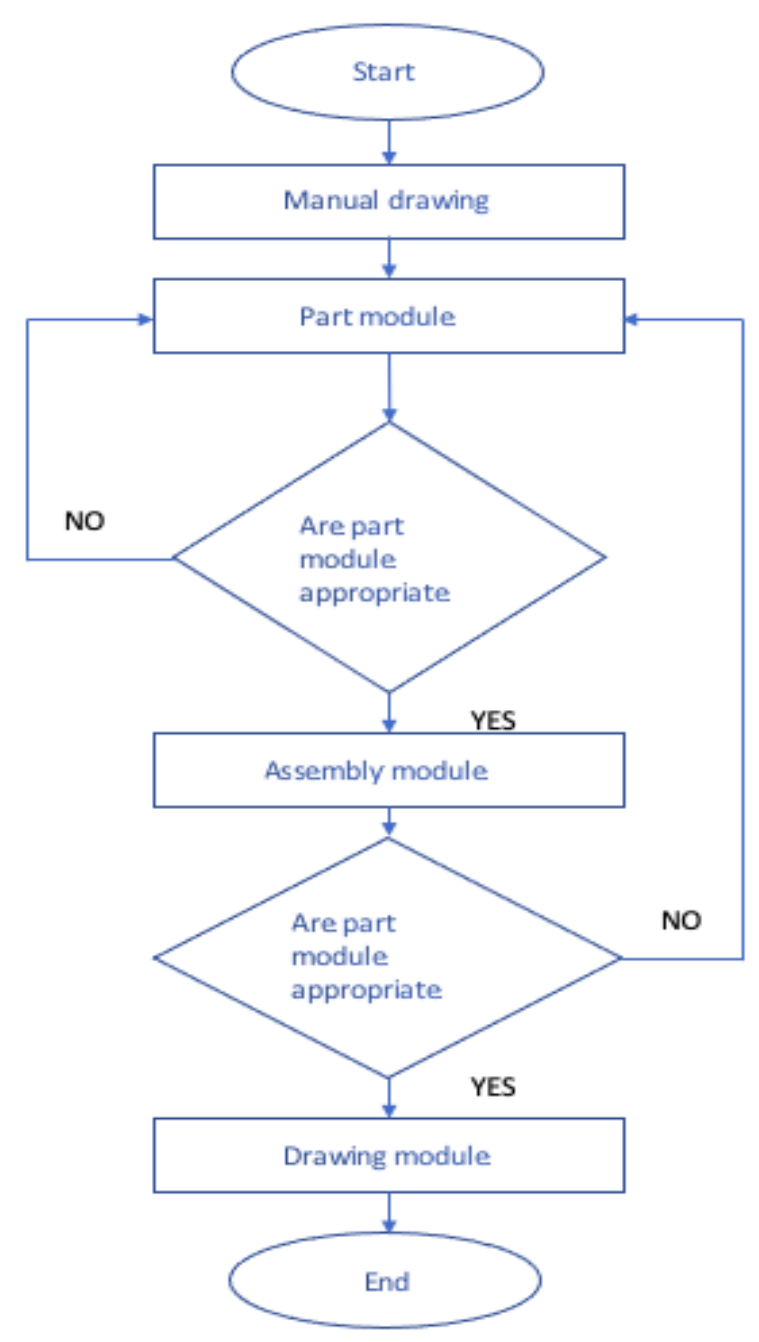

Fig. 1. Block Diagram of Control unit 


\section{SOILD WORK DESIGN}

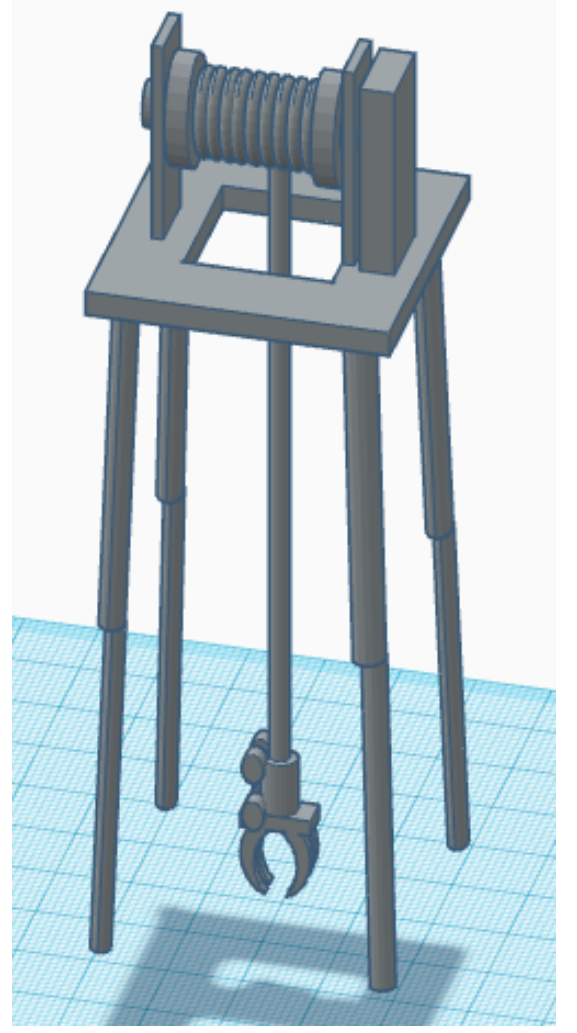

Fig. 2. CAD Design

\section{DESIGN DETAILS}

Total length of the robot is $130 \mathrm{cms}$. It contained four legs which height is $96 \mathrm{cms}$ which is providing stability at any surface. Flexible pipe wounding bobbin rest on $40 \times 40 \mathrm{cms}$ base. This bobbin provides pull operation to robotic arm. Whole robotic arm length is $100 \mathrm{cms}$. By this robotic arm we perform main cleaning action. Main part of this robotic arm which contained two teeth which grab any object. This tooth get powered through linear motor. This prat dimension is $20.85 \mathrm{cms}$. For carrying this robotic arm in drainage at horizontal direction we design a simple 4 wheel drive robot which is provide us better movement under drainage.

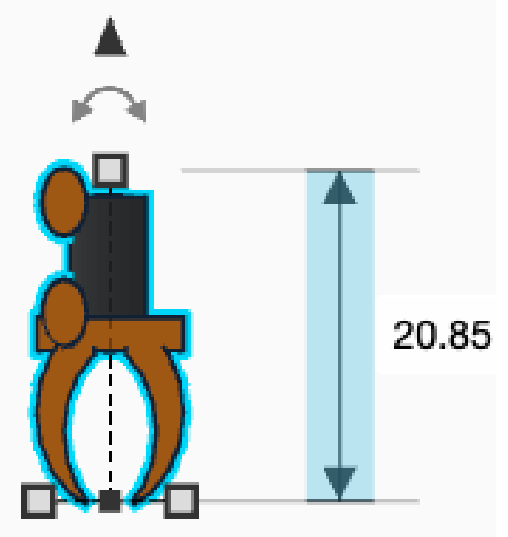

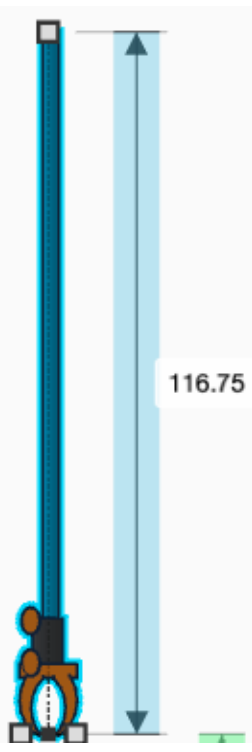
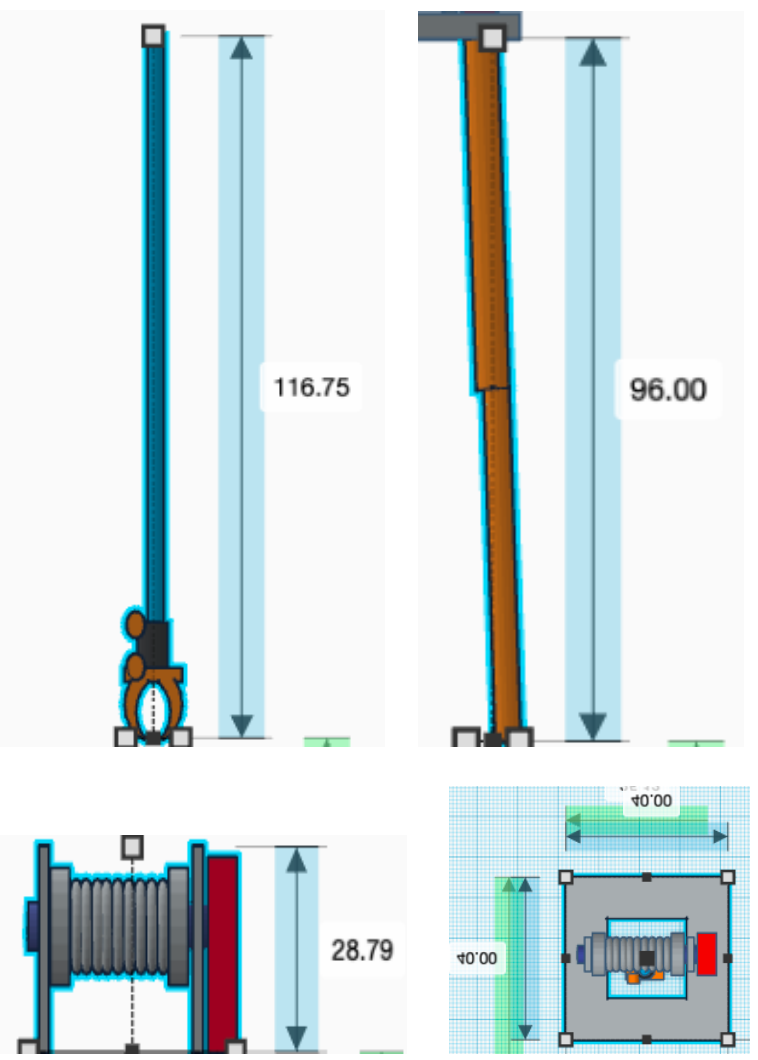

Fig. 3.

\section{SIMULATION WORK}

\section{A. Main robotic Arm operation}

In this simulation we used Tinkercad solid work software to perform this work. In working when we provide electric supply to the motor, motor start rotating. As we previously defined, we use linear action motor that means its shaft not act linear action but we built a mechanism which act linear action. This linear power gives to the robotic arm mainly to the teeth. By this power teeth will close and open because of this linear motor.

When power applied to the motor, motor start running as per the calculation we determined that for full expansion of teeth required 4 turns of motor shaft. This motoring action done by using PWM modulation. PWM modulation provide us very smooth action and speed varieties. For generating PWM pulse we used ATmega2560 microcontroller

\section{B. Main motor PWM operation mode}

For generating PWM pulse we used ATmega2560 microcontroller. For perform this simulation we also used Tinkercad software.

Pulse width modulation is basically help us to run motor at various speed. It also provide us smooth operation 


\section{CONCLUSION}

In this paper we have designed drainage cleaning robotics system using tinkercad solid work software and a simple four wheel drive robot which is provide for better movement under drainage.

\section{ACKNOWLEDGMENT}

I would like to express my special thankfulness towards my project member who have contributed their valuable effort or completing our project work and also thanks for our guide who gave me the opportunity to do this wonderful project on Drainage Cleaning Robotics system using tinkercad solid work software which also helped me for providing facilities that was required.

\section{REFERANCE}

[1] Sanjay Kumar Chaudhary, "Dignity defined, Law and Policies for Manual Scavengers", 2011.

[2] Nathan Hurst (18 Mav 2013). "Autodesk Purchases, Revives 3-D Design App Tinkercad". Wired.com.

[3] "Robot Arm and Computer Vision". Retrieved 29 July 2016.

[4] "Tinkercad uses WebGL. a new 3D web standard". Archived from the original on 14 May 2012.
TABLE I. RESULTS OF SIMULATION

\begin{tabular}{|c|c|l|c|c|c|}
\hline \multirow{2}{*}{ Sr. No. } & \multirow{2}{*}{ Motors } & \multicolumn{4}{|c|}{ Operation in Modes } \\
\cline { 3 - 6 } & & action & angle & turns & voltage \\
\hline 1 & motor & clockwise & - & 4 & 7.94 \\
\hline 2 & teeth & expansion & $\begin{array}{c}120 \\
\text { degree }\end{array}$ & - & - \\
\hline 3 & motor & clockwise & - & 3 & 7.94 \\
\hline 4 & teeth & expansion & 90 degree & - & - \\
\hline
\end{tabular}

